\title{
Optimization of operational parameters for ethanol production from Korean food waste leachate
}

\author{
H. Le Man; S. K. Behera; ${ }^{*}$ H. S. Park \\ Ecosystems Laboratory, Department of Civil and Environmental Engineering, \\ University of Ulsan, Ulsan 680749, South Korea
}

Received 20 September 2009; $\quad$ revised 22 October 2009; accepted 12 November 2009; available online 1 December 2009

\begin{abstract}
Recently, research on the production of ethanol from waste has been accelerating for both ecological and economical reasons, primarily for its use as an alternative to petroleum based fuels. In this study, response surface methodology based $2^{3}$-full factorial central composite design was employed to optimize the parameters of ethanol production from Korean food waste leachate. The reducing sugar concentration of the food waste leachate determined by the dinitrosalicylic acid method was $75 \mathrm{~g} / \mathrm{L}$. A second order polynomial model was developed to evaluate the quantitative effects of temperature, $\mathrm{pH}$ and reducing sugar concentration in order to find an optimum condition for the ethanol production from food waste leachate. From the experimental result, maximum ethanol concentration of 24.17 $\mathrm{g} / \mathrm{L}$ was obtained at the optimum condition of temperature $\left(38^{\circ} \mathrm{C}\right), \mathrm{pH}(5.45)$ and reducing sugar concentration $(75 \mathrm{~g} / \mathrm{L})$. The experimental value $(24.17 \mathrm{~g} / \mathrm{L})$ agreed very well with the predicted one $(23.66 \mathrm{~g} / \mathrm{L})$, indicating the suitability of the model employed and the success of response surface methodology in optimizing the conditions of ethanol production from food waste leachate. Canonical analysis indicated that the stationary point was a saddle point for the ethanol yield. Despite being a waste, an ethanol yield of $0.32 \mathrm{~g}$ ethanol/g reducing sugar demonstrated the potential of food waste leachate as a promising biomass resource for the production of ethanol.
\end{abstract}

Keywords: Fermentation; pH; Reducing sugar concentration; Response surface methodology; Saccharomyces cerevisiae; Temperature

\section{INTRODUCTION}

The amount of food waste generated in Korea is approximately 13000 tons, accounting for $27 \%$ of total municipal solid waste (Lee et al., 2009). The disposal of food waste assumed significance and became a major concern in Korea since 2005 when the environmental law prohibited the sanitary landfilling of such wastes (Kim et al., 2008). Therefore, food waste recycling facilities were installed in the country to mitigate the food waste disposal problem. However, $70-90 \%$ of the food waste treated in the food waste recycling facilities takes the form of a dense, malodorous liquid called food waste leachate (FWL). The FWL with a volatile solid (VS) concentration of $\sim 15 \%$ is currently being discharged to the ocean that has serious adverse effect on the marine ecosystem.

Furthermore, the Korean government is heading for prohibiting the marine disposal of such type of organic wastes by the year 2012 (Lee et al., 2009). Thus, there

ه*Corresponding Author Email: parkhs@ulsan.ac.kr

Tel.: +8252 259 1050; Fax: +8252 2210152 is an urgent need to alleviate this problem causing serious concern recently.

Bioethanol is one of the promising future energy alternatives contributing to the reduction of negative environmental impacts generated by the use of fossil fuels (McMillan, 1997). It can be produced from a variety of raw materials containing fermentable sugars. However, the utilization of energy-rich crops such as corn and sugar cane, as feedstock for generating ethanol, may jeopardize the food security in any country and is a debated issue at the moment. Besides, the utilization of virgin resources enhances the total cost of ethanol production to a large extent. Therefore, biomass wastes such as corn fiber, waste wood, waste cardboard and paper sludge, molasses, bread residues, bagasse (Teixeira et al., 1999; Iranmahboob et al., 2001; Kádár et al., 2004; Cazetta et al., 2007; Ebrahimi et al., 2007; Gaspar et al., 2007) and FWL are far more attractive as cheap feedstocks for ethanol production than virgin resources. For instance, Kádár et al., (2004) 
examined the simultaneous saccharification and fermentation of waste cardboard and paper sludge produces ethanol in the range of 0.31-0.34 g/g waste. The bread residues can be fermented to get the ethanol yield around $0.35 \mathrm{~g} / \mathrm{g}$ substrate (Ebrahimi et al., 2007). Wilkins et al., (2007) reported that the citrus peel waste can undergo steam explosion process to remove the ${ }_{D}$ limonene and subsequently can be consumed by the Saccharomyces cerevisiae to get ethanol yield of $0.33 \%(\mathrm{v} / \mathrm{v})$.

Being enormously generated in the recycling facilities and very rich in sugar content $(75 \mathrm{~g} / \mathrm{L}$, Table 1) FWL can be utilized as a potential substrate for the production of ethanol. Reports exist on the production of ethanol by fermentation of fresh kitchen garbage using Saccharomyces cerevisiae as inoculum (Tang et al., 2008; Wang et al., 2008). However, FWL is different from fresh kitchen garbage being contaminated in nature. Therefore, optimal production of ethanol from FWL is challenging and is a key subject pertaining to a variety of fermentation conditions.

The conventional approach for the optimization of a multivariable system is usually one-variable-at-a-time. However, such approach needs to carry out numerous sequential experimental runs and cannot explain the interactions between the variables. Recently many statistical experimental design methods have been employed in bioprocess optimization. Response surface methodology (RSM) is one such scientific approach that is useful for developing, improving and optimizing processes and is used to analyze the effects of several independent variables on the system response, main objective being the determination of optimum operational conditions within the operating specifications (Ravikumar et al., 2005; Jo et al., 2008). This method has been successfully applied to optimize alcoholic fermentation process (Castillo et al., 1982; Ratnam et al., 2003). In the present study, the RSM based central composite design (CCD) was applied to identify the optimum condition of the FWL fermentation

Table 1: Characteristics of FWL

\begin{tabular}{lcc}
\hline Test parameters & Unit & Average value \\
\hline Total solids (TS) & $\%$ & 16.0 \\
Volatile solids (VS) & $\%$ & 14.6 \\
Moisture Content (MC) & $\%$ & 84.0 \\
RSC & $\mathrm{g} / \mathrm{L}$ & 75.0 \\
$\mathrm{pH}$ & - & 5.0 \\
\hline
\end{tabular}

process by evaluating the effects of temperature Laboratory, $\mathrm{pH}$, and reducing sugar concentration (RSC) during ethanol production using $S$. cerevisiae (7904) as the inoculum. This research was carried out in Ecosystems Laboratory, University of Ulsan, South Korea during October 2007 to March 2008.

\section{MATERIALS AND METHODS}

Microorganism and FWL

The FWL was collected from Sung-am food waste resource recovery plant, Ulsan, South Korea. Saccharomyces cerevisiae obtained from the Korea Research Institute of Bioscience and Biotechnology, Daejon, Korea was used in all experiments (Le Man et al., 2008). The strain (7904) was cultivated in the growth medium for a period of $48 \mathrm{~h}$. It was kept under sterile conditions, at neutral $\mathrm{pH}$ and $35^{\circ} \mathrm{C}$ in an incubating shaker run at $150 \mathrm{rpm}$. The cell concentration in the cultivated medium was $2.3 \times 10^{8}$ cells $/ \mathrm{mL}$. The growth medium used for cultivation of inoculum culture consisted of (in $\mathrm{g} / \mathrm{L}$ ): glucose 10 , yeast extract 3 , malt extract 3 and peptone 3 (Nahvi et al., 2002).

\section{Ethanol production}

Collected FWL was thoroughlyblended in a mixer and then sterilized in an autoclave (Vision Scientific Co. Ltd., South Korea) at $120^{\circ} \mathrm{C}$ for $15 \mathrm{~min}$. The $\mathrm{pH}$ was adjusted using $1 \mathrm{~N} \mathrm{H}_{2} \mathrm{SO}_{4}$ and $1 \mathrm{~N} \mathrm{NaOH}$ and RSC was adjusted either by diluting with water or by adding glucose. Batch experiments were carried out in a series of $500 \mathrm{~mL}$ Erlenmeyer flasks, containing $200 \mathrm{~mL}$ of FWL. $2.5 \%$ inoculum culture was dispensed to each flask. The temperature, $\mathrm{pH}$ and RSC were varied between 26.6-43. $4^{\circ} \mathrm{C}$, 3.31-6.68 and 34.77-85.23 g/L, respectively. The flasks were shaken at $180 \mathrm{rpm}$ in a thermostat controlled incubating shaker (iNtRON Biotechnology Co. Ltd., South Korea) under the designed temperatures for $40 \mathrm{~h}$. Experiments were carried out in duplicate for all the runs and the average values were subjected to model analysis. Besides, as a statistical measure, 6 experiments were conducted at the centerpoint to check for any error.

\section{Analytical \\ Characterization of FWL}

Analysis of total solid (TS) and VS of samples were carried out in accordance with standard methods (APHA, 1998). The $\mathrm{pH}$ of the samples was measured 
by a pH meter (420A, Orion 3-star series; Thermo scientific, MA, USA). RSC was determined using the dinitrosalicylic acid (DNS) method (Miller, 1959).

\section{Ethanol concentration estimation}

Ten $\mathrm{mL}$ of fermentation broth was centrifuged at $5000 \mathrm{rpm}$ for $30 \mathrm{~min}$ at $10^{\circ} \mathrm{C}$ and the supernatant was used to estimate the ethanol concentration. Ethanol was analyzed by gas chromatography(HP-5960, Global Medical Instrumentation Inc, MN, USA) equipped with $\mathrm{CP}-$ Wax column at $110^{\circ} \mathrm{C}$, flame ion detector (FID) $220^{\circ} \mathrm{C}$ and injector $170^{\circ} \mathrm{C}$. Nitrogen was used as carrier gas at a flow rate of $30 \mathrm{~cm}^{3} / \mathrm{min}$ and the combustion gas was a mixture of hydrogen and air.

\section{Statistical design of experiments}

Experiments with three independent variables temperature $\left(\mathrm{X}_{1}\right), \mathrm{pH}\left(\mathrm{X}_{2}\right)$ and $\mathrm{RSC}\left(\mathrm{X}_{3}\right)$ were conducted (Table 2) using the experimental design obtained by the full factorial CCD. In this study, the full CCD consisted of (i) a complete $2^{3}$-factorial design, (ii) $n_{0}$, center point $\left(n_{0}>1\right)$ and (iii) two axial points on the axis of each design variable at a distance of $\alpha=1.682$ from the design centre. Hence a total number of design points of $N=2^{k}+2 k+n_{0}$ was used. The center point was replicated six times to give five degrees of freedom for calculation of errors in the experiments. The optimal values of the experimental conditions were obtained by solving the regression equation and by analyzing the response surface contour plots. The variables were coded according to the Eq. 1:

$$
X_{i}=\frac{x_{i}-x_{0}}{\Delta x}
$$

Where, $X_{i}$ is the coded value of variable i, $x_{i}$ the uncoded real value of an independent variable, $x_{0}$ the value of $X_{i}$ at the center point and $D x$ is the step change between levels 0 and 1 . The behavior of the system was explained by the following second order polynomial equation:

$Y=\beta_{0}+\sum_{i=1}^{3} \beta_{i} X_{i}+\sum_{i=1}^{3} \beta_{i i} X_{i}^{2}+\sum_{i, j=1(i \neq j)}^{3} \beta_{i j} X_{i} X_{j}$

Table 2: Independent variables of fermentation conditions

\begin{tabular}{lrrrrr}
\hline Variables & \multicolumn{5}{c}{ Coded levels } \\
\cline { 2 - 6 } & -1.682 & -1 & 0 & 1 & 1.682 \\
Temp. $\left(\mathrm{X}_{1}{ }^{\circ} \mathrm{C}\right)$ & 26.60 & 30 & 35 & 40 & 43.40 \\
pH $\left(\mathrm{X}_{2}\right)$ & 3.31 & 4 & 5 & 6 & 6.68 \\
RSC $\left(\mathrm{X}_{3}, \mathrm{~g} / \mathrm{L}\right)$ & 34.77 & 45 & 60 & 75 & 85.23 \\
\hline
\end{tabular}

Where, $Y$ is the ethanol concentration, $\beta_{0}$ the offset term, $\beta_{i}$ the coefficient of linear effect, $\beta_{i i}$ the coefficient of squared effect, $\beta_{i j}$ the coefficient of interaction effect and $X_{j}$ is the coded value of variable $\mathrm{j}$.

The goodness-of-fit of the regression model and the significance of parameters estimates were determined through appropriate statistical methods. Statistical calculations and analysis were done using the software MINITAB (Version 14.12, PA, USA).

\section{RESULTS AND DISCUSSION}

To evaluate the potential of ethanol yield from FWL, 20 experiments were conducted according to the CCD method (Table 3).

Six experiments (runs 15-20) were replicated at the center point to verify any change in the estimation procedure as a measure of the precision property. Generally the parameters that predominantly affect the ethanol yield in a fermentation process are temperature, pH and RSC (King and Hossain, 1982). To study the combined effects of these factors, experiments were performed at different combinations of these parameters using statistically designed experiments.

\section{The second-order model and ANOVA}

The results from this study helped to frame a second order polynomial equation (Eq. 3) (in coded units) that relates the ethanol concentration, Y (g/L)

Table 3: $2^{3}$-full factorial CCD for ethanol yield

\begin{tabular}{|c|c|c|c|c|c|}
\hline \multirow{2}{*}{ Run no. } & \multirow{2}{*}{$\mathrm{X}_{1}$} & \multirow{2}{*}{$\mathrm{X}_{2}$} & \multirow{2}{*}{$\mathrm{X}_{3}$} & \multicolumn{2}{|c|}{ Ethanol conc., Y (g/L) } \\
\hline & & & & Observed & Predicted \\
\hline 1 & -1 & -1 & -1 & 10.21 & 8.36 \\
\hline 2 & 1 & -1 & -1 & 12.93 & 11.25 \\
\hline 3 & -1 & 1 & -1 & 10.49 & 11.20 \\
\hline 4 & 1 & 1 & -1 & 10.76 & 10.38 \\
\hline 5 & -1 & -1 & 1 & 13.36 & 12.70 \\
\hline 6 & 1 & -1 & 1 & 23.56 & 21.81 \\
\hline 7 & -1 & 1 & 1 & 17.82 & 18.46 \\
\hline 8 & 1 & 1 & 1 & 23.05 & 23.86 \\
\hline 9 & -1.682 & 0 & 0 & 10.28 & 10.46 \\
\hline 10 & 1.682 & 0 & 0 & 16.15 & 17.43 \\
\hline 11 & 0 & -1.682 & 0 & 10.65 & 13.68 \\
\hline 12 & 0 & 1.682 & 0 & 19.35 & 17.79 \\
\hline 13 & 0 & 0 & -1.682 & 6.24 & 7.64 \\
\hline 14 & 0 & 0 & 1.682 & 22.56 & 22.63 \\
\hline 15 & 0 & 0 & 0 & 18.22 & 17.97 \\
\hline 16 & 0 & 0 & 0 & 18.20 & 17.97 \\
\hline 17 & 0 & 0 & 0 & 18.03 & 17.97 \\
\hline 18 & 0 & 0 & 0 & 17.88 & 17.97 \\
\hline 19 & 0 & 0 & 0 & 17.83 & 17.97 \\
\hline 20 & 0 & 0 & 0 & 17.91 & 17.97 \\
\hline
\end{tabular}




$$
\begin{aligned}
& Y=17.9697+2.0716 X_{1}+1.2222 X_{2}+4.4554 X_{3} \\
& -1.4219 X_{1}^{2}-0.7908 X_{2}^{2}-1.0029 X_{3}^{2} \\
& -0.9275 X_{1} X_{2}+1.555 X_{1} X_{3}+0.73 X_{2} X_{3}
\end{aligned}
$$

to the initial conditions of temperature, $\mathrm{pH}$ and RSC. This equation was used to predict the ethanol concentration in Table 3. Apart from explaining the linear effects of temperature, $\mathrm{pH}$ and $\mathrm{RSC}$ on ethanol yield, the CCD approach described the quadratic and interaction effects of the parameters too.

ANOVA is important in determining the adequacy and significance of the quadratic model. The analyses were done by means of Fisher's ' $F$ '-test. Generally the ' $F$ ' value with a low probability ' $P$ ' value indicates high significance of the regression model (Rene et al., 2007). From the ANOVA summary (Table 4), the model was found to be statistically significant $(\mathrm{P}<0.01)$ at the $99 \%$ confidence level. Due to the lowest ' $\mathrm{P}$ ' value $(\mathrm{P}=$ 0 ), the linear effects were highly significant compared to the quadratic $(\mathrm{P}=0.017)$ and interaction $(\mathrm{P}=0.047)$ effects. Thus, the ethanol concentration was adequately explained by the model equation (Eq.3). Alternatively, the fitting of the experimental data to the regression model was checked and suitably explained by the value of determination coefficient $\left(\mathrm{R}^{2}=0.94\right)$. It indicated that $\sim 6 \%$ of the total variations in the ethanol concentration were not satisfactorily explained by the model (Eq. 3). This unexplained value of response ( $\sim 6 \%$ ) was presented in terms of residual error in the ANOVA table (Table 4). Though this value would be considered low in applied statistics, it can be accepted and be attributed to the complex biotransformation of waste during the fermentation process. In their work, Chauhan and Gupta (2004) have emphasized on the acceptance of any model with $\mathrm{R}^{2}$

$>0.75$. Besides, the relationship between the

Table 4: ANOVA of the model

\begin{tabular}{lrrrrl}
\hline Source & DF & \multicolumn{1}{c}{ Seq SS } & Adj SS & \multicolumn{1}{c}{ F } & P \\
\hline Regression & 9 & 425.340 & 425.340 & 17.61 & 0.000 \\
Linear & 3 & 350.109 & 350.109 & 43.48 & 0.000 \\
Square & 3 & 44.742 & 44.742 & 5.56 & 0.017 \\
Interaction & 3 & 30.489 & 30.489 & 3.79 & 0.047 \\
Residual & 10 & 26.841 & 26.841 & & \\
error & 5 & 26.701 & 26.701 & 190.88 & 0.000 \\
Lack-of-fit & 5 & 0.140 & 0.140 & & \\
Pure error & 19 & 452.181 & & & \\
Total & & & & & \\
\hline
\end{tabular}

DF: degrees of freedom; Seq SS: sequential sum of squares; Adj SS: adjusted sum of squares; F: Fischer's variance ratio; P: probability value. experimental values and predicted values (Fig.1) showed that the plotted points cluster around the diagonal line, indicating good fitness of the model.

Each item in the regression model (Eq. 3) has an identified effect on the ethanol concentration. Students ' $t$ '-test can be used to quantify the intensity of parameters (temperature, pH and RSC) on the ethanol concentration, while ' $\mathrm{P}$ ' values signify the pattern of interaction among the parameters. The larger the value of ' $\mathrm{t}$ ' and the smaller the value of ' $\mathrm{P}$ ', the more significant is the corresponding coefficient term (Douglas, 2001). The regression coefficients and ' $t$ ' and ' $\mathrm{P}$ ' values for all the linear, quadratic and interaction effects of the parameters are given in Table 5. A positive sign in the ' $t$ ' value indicated a synergistic effect, while a negative sign represented an antagonistic effect of the parameters on the ethanol concentration. Ethanol concentration was significantly affected by the synergistic effect of the linear terms of RSC, with a 'P'-

Table 5: Estimated regression coefficients, 't'- and ' $\mathrm{P}$ '-values of the model

\begin{tabular}{llcccl}
\hline Relationship & & Factor & Coefficient & 't'-Value & 'P'-Value \\
\hline Main effects & Linear & $\mathrm{X}_{1}$ & 2.0716 & 4.673 & $0.001^{* * *}$ \\
& Linear & $\mathrm{X}_{2}$ & 1.2222 & 2.757 & $0.020^{* * *}$ \\
& Linear & $\mathrm{X}_{3}$ & 4.4554 & 10.050 & $0.000^{* * *}$ \\
Interactions & Pure & $\mathrm{X}_{1}{ }^{2}$ & -1.4219 & -3.295 & $0.008^{* * *}$ \\
& quadratic & $\mathrm{X}_{2}{ }^{2}$ & -0.7908 & -1.832 & $0.097^{*}$ \\
& & $\mathrm{X}_{3}{ }^{2}$ & -1.0029 & -2.324 & $0.042^{* *}$ \\
& Cross & $\mathrm{X}_{1} \mathrm{X}_{2}$ & -0.9275 & -1.601 & 0.140 \\
& product & $\mathrm{X}_{1} \mathrm{X}_{3}$ & 1.5550 & 2.685 & $0.023^{*}$ \\
& & $\mathrm{X}_{2} \mathrm{X}_{3}$ & 0.7300 & 1.260 & 0.236
\end{tabular}

"Significant at $10 \%$ ('P'-Value); ${ }^{* *}$ Significant at 5\% ('P'-Value); and ${ }^{* * *}$ Significant at $1 \%$ ('P'-Value). (+): synergistic effect ('t'-Value) (-): antagonistic effect ('t'-Value)

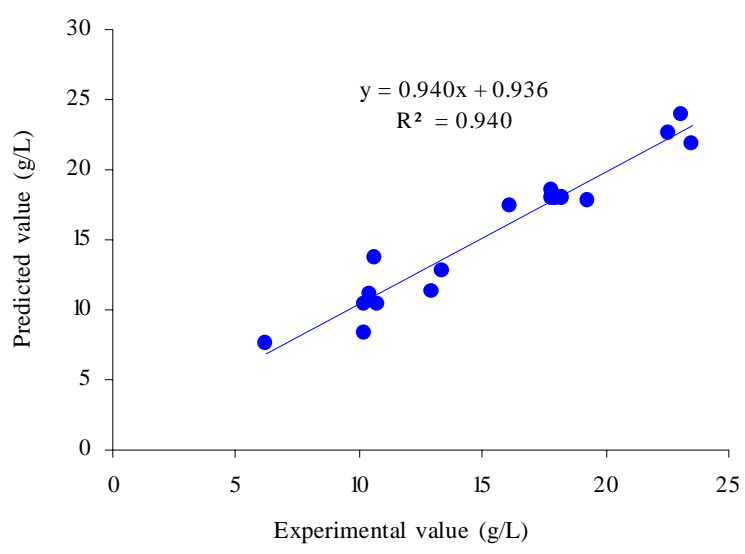

Fig. 1: Parity plot showing the distribution of experimental and predicted values of ethanol concentration 
This result suggested that the RSC had a direct relationship with the production of ethanol from FWL, i.e. any minor change in this variable may cause a great positive or negative change in ethanol concentration. Besides, the quadratic terms $\left(\mathrm{X}_{1}^{2}, \mathrm{X}_{2}{ }^{2}\right.$ and $\left.\mathrm{X}_{3}{ }^{2}\right)$ showed the antagonistic effects on the ethanol concentration, typically $\mathrm{X}_{1}^{2}(\mathrm{P}=0.008)$.

\section{Response surface plots and optimization conditions}

The ultimate objective of CCD method used in this study was to find out the significant effects of the parameters viz., temperature, $\mathrm{pH}$ and RSC and trace the optimum condition for ethanol production from FWL. Surface and contour plots demonstrating the effects of different process parameters, two parameters varied at a time while keeping the third at middle level, on the ethanol concentration were shown in Figs. 2-4. The stationary points were examined by analyzing these plots. Generally, circular contour plots indicate that the interactions between parameters are negligible. On the contrary, elliptical ones indicate the evidence of the interactions (Muralidhar et al., 2003).

Fig. 2 showed the effect of temperature and $\mathrm{pH}$ on the ethanol concentration. The convex response surface suggested well-defined optimum variables (temperature and $\mathrm{pH}$ ) and that the ethanol concentration increased to the peak with the increase of temperature and $\mathrm{pH}$ up to $38^{\circ} \mathrm{C}$ and 5.45, respectively; then declined with the further increase of these two parameters. This result demonstrated that the response surface had a maximum point for ethanol yield. Similar results have been obtained by Wilkins et al., (2007) who reported that ethanol production from simultaneous saccharification and fermentation of citrus peel waste by $S$. cerevisiae was greatest when the fermentation temperature and $\mathrm{pH}$ were adjusted to $37^{\circ} \mathrm{C}$ and 6.0, respectively. Besides, higher ethanol productivity from the kitchen waste using $S$. cerevisiae KF-7 as inoculum has been reported at the fermentation conditions of temperature $\left(37^{\circ} \mathrm{C}\right)$ and $\mathrm{pH}$ (5.85) (Tang et al., 2008).

$S$. cerevisiae is reported to grow well within the temperature range $28-40{ }^{\circ} \mathrm{C}$ (Rivera et al., 2006). The increase in temperature accelerates the inhibition effect of the RSC and ethanol on the cell activities, thereby lowering both cell and ethanol yields (Phisalaphong et al., 2005). The deleterious effect of higher temperatures on ethanol yield can be attributed to the denaturation of ribosomes and enzymes and problems associated with the fluidity of membranes (McMeckin et al., 2002).
The inhibitory effect of $\mathrm{pH}$ (at the high level) on the ethanol yield could be due to the lower ATP production during the metabolic changes in $S$. cerevisiae (Pena et al., 1972). During the investigation for ethanol production from various waste resources viz., bread residue, citrus peel, kitchen garbage and pineapple cannery waste, $S$. cerevisiae was found to grow well within the range of $\mathrm{pH} 4.18$ - 6 (Nigam, 2000; Ebrahimi et al., 2007; Wilkins et al., 2007; Wang et al., 2008).

The effects of other two pairs viz. temperatureRSC and pH-RSC on the ethanol concentration formed the stationary ridge systems as shown in Fig. 3 and Fig. 4, respectively. It can be observed from these Figs that, within the range of experiment (Temperature: 26.59 - $43.41{ }^{\circ} \mathrm{C}, \mathrm{pH}: 3.31$ - 6.68), any changes in temperature and $\mathrm{pH}$ had a small difference in the ethanol concentration, while the change in RSC had a significant effect on the ethanol concentration. With increase in RSC from 34.77 to $85.23 \mathrm{~g} / \mathrm{L}$, the ethanol concentration increased from 7.64 to $22.63 \mathrm{~g} / \mathrm{L}$ (Table $3)$. This result indicated that there was no inhibition to the ethanol yield by the increase in RSC. While producing ethanol from cheese-whey powder, Ozmihci and Kargi (2007) reportedly kept the sugar concentration below $75 \mathrm{~g} / \mathrm{L}$ to avoid substrate inhibition due to osmotic stress on the Kluyveromyces marxianus (DSMZ-7239). During the investigation for ethanol production by $S$. cerevisiae M30 using cane molasses as the substrate, the significant effect of RSC on ethanol yield was observed at a concentration of $22 \%$ (w/v) (Phisalaphong et al., 2005).

The stationary ridge systems observed in Figs. 3 and 4 were analyzed based on the canonical form of the second-order model. The nature of the response surfaces were described by the following equation:

$y=23.659-3.329 w_{1}^{2}-0.248 w_{2}^{2}+0.362 w_{3}^{2}$

Where, $\mathrm{w}_{1}, \mathrm{w}_{2}$ and $\mathrm{w}_{3}$ are the axes of the response surface. The eigen values $\lambda_{1}(-3.329)$ is negative; $\lambda_{2}$ $(-0.2484)$ and $\lambda_{3}(0.3619)$ were closed to zero that makes the surface a rising ridge system and the stationary point was a saddle point for the response. Also, the two eigen values closed to zero $\left(\lambda_{2}\right.$ and $\left.\lambda_{3}\right)$ indicate that the plane in the $\left(\mathrm{w}_{2}, \mathrm{w}_{3}\right)$ coordinates will be closed to the optimal operating conditions. The maximum point in the ethanol yield can be achieved by increasing the RSC under the 
H. Le Man et al.

(a)
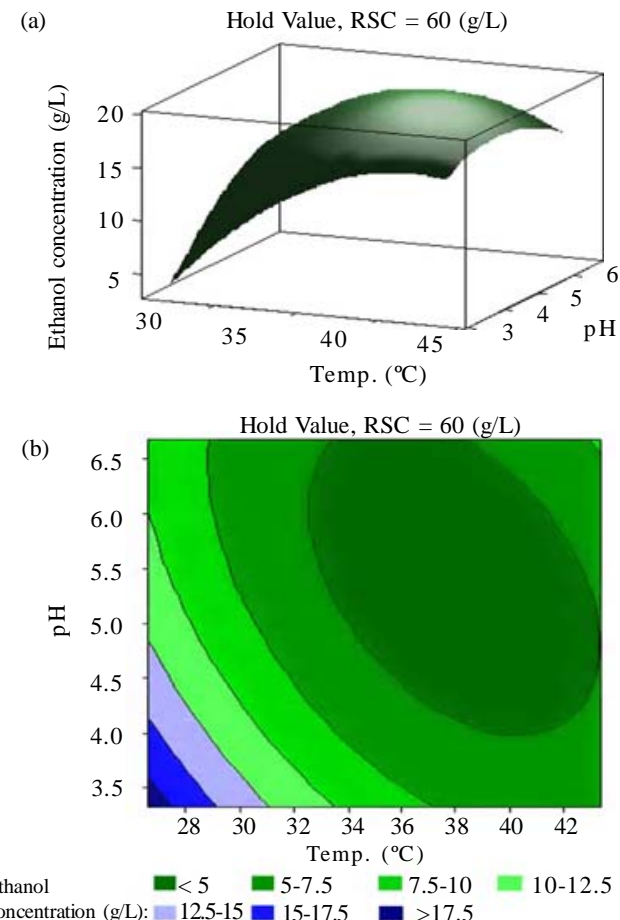

Fig. 2: Interaction effects of temperature and $\mathrm{pH}$ on ethanol concentration: (a) surface plot (b) contour plot

(a)

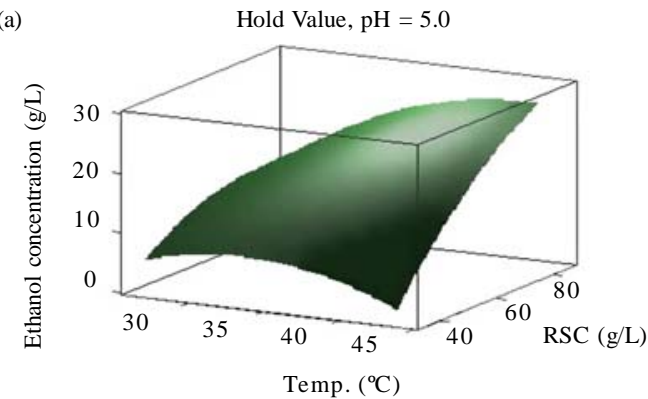

(b)

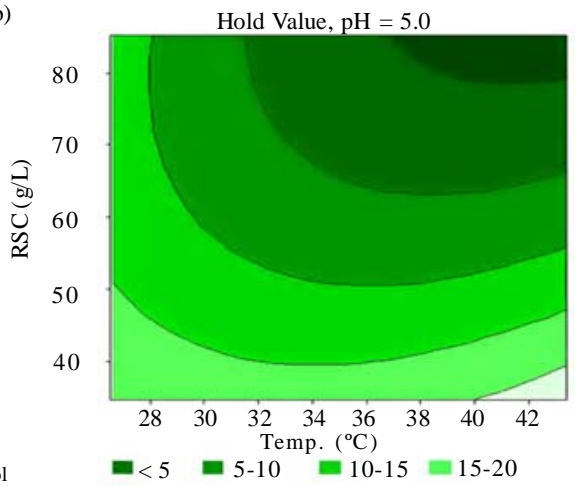

concentration $(g / \mathrm{L}):=20-25>25$

Fig. 3: Interaction effects of temperature and RSC on ethanol concentration: (a) surface plot and (b) contour plot (a)

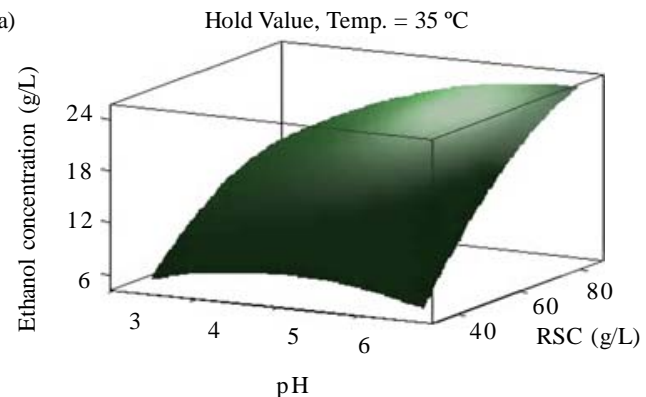

(b)

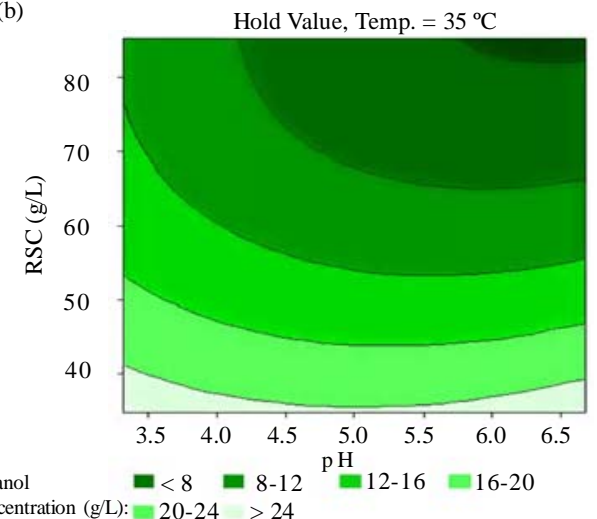

Fig. 4: Interaction effects of $\mathrm{pH}$ and RSC on ethanol concentration: (a) surface plot and (b) contour plot

steepest ascent method (Douglas, 2001). However, the addition of sugar (glucose) to the contaminated medium for ethanol fermentation is meaningless in real practice. Therefore, the RSC of FWL (+1 level, Table 2) can be chosen as the optimum value in this study.

\section{Model validation and confirmation}

To confirm the validity of the statistical experimental strategies and gain a better understanding of ethanol yield from FWL, a confirmation experiment with duplicate set was performed at the specified optimum condition. Experiments conducted at the optimum condition (Temperature: $38{ }^{\circ} \mathrm{C}, \mathrm{pH}: 5.45$ and RSC of $75 \mathrm{~g} / \mathrm{L})$ demonstrated that the ethanol concentration (24.17 g/L) was closer to the predicted value (23.66 $\mathrm{g} / \mathrm{L})$. Corresponding to the ethanol concentration of $24.17 \mathrm{~g} / \mathrm{L}$, the ethanol yield was calculated as $0.32 \mathrm{~g}$ ethanol/g reducing sugar accounting for as high as $63 \%$ of the stoichiometric value. This showed that the model was useful to predict the ethanol concentration as well as optimize the experimental conditions. 


\section{CONCLUSION}

The present study using RSM based CCD established an efficient second order polynomial model to describe the ethanol yield by FWL fermentation. The high similarity between the experimental value and the predicted ones $\left(\mathrm{R}^{2}=0.94\right)$ suggested that the model was a good fit. Maximum ethanol concentration of $24.17 \mathrm{~g} / \mathrm{L}$ was obtained at the optimum condition of temperature $\left(38^{\circ} \mathrm{C}\right), \mathrm{pH}(5.45)$ and RSC $(75 \mathrm{~g} / \mathrm{L})$. The ethanol concentration at the optimum experimental condition $(24.17 \mathrm{~g} / \mathrm{L})$ agreed well with the predicted one $(23.66 \mathrm{~g} / \mathrm{L})$. This indicated the suitability of the model employed and the success of RSM to optimize the conditions of ethanol production from FWL. Corresponding to the ethanol concentration of 24.17 $\mathrm{g} / \mathrm{L}$, the ethanol yield from the FWL was obtained as $0.32 \mathrm{~g}$ ethanol/g reducing sugar. This research lays down the basis for ethanol production from the FWL despite being a contaminated substrate. The results from the investigation showed that FWL can be used as an alternative substrate for ethanol production, in comparison to virgin biomass resources such as energy-rich crops, if sterilized suitably prior to fermentation by some low cost energy sources such as excess heat or waste heat from some industrial processes adjacent to ethanol production facility. Further research is, however, warranted to examine the economical viability of the process.

\section{ACKNOWLEDGEMENTS}

Financial support for this research from Korea Research Foundation (KRF 2007-D00066-100229) is greatly acknowledged. Analytical facility provided by Prof. Eun Woo Shin and NURI office, University of Ulsan is appreciated.

\section{REFERENCES}

APHA, (1998). Standard Methods for Examination of Water and Wastewater, 20 $0^{\text {th }}$ Ed., American Public Health Association, Washington, D.C.

Castillo, F. J.; Izaguirre, M. E.; Michelena, V.; Moreno, B., (1982). Optimization of fermentation conditions for ethanol production from whey. Biotech. Lett., 4 (9), 567 572 (6 pages)

Cazetta, M. L.; Celligoi, M. A. P. C.; Buzato, J. B.; Scarmino, I. S., (2007). Fermentation of molasses by Zymomonas mobilis: Effects of temperature and sugar concentration on ethanol production. Bioresour. Tech., 98 (15), 2824-2828 (5 pages).

Chauhan, B.; Gupta. R., (2004). Application of statistical experimental design for optimization of alkaline protease production from Bacillus sp. RGR-14. Proc. Biochem., 39 (12), 2115-2122 (8 pages).
Douglas, C. M., (2001). Design and analysis of experiments. $5^{\text {th. }}$ Ed. John Wiley and Sons, Arizona, USA.

Ebrahimi, F.; Khanahmadi, M.; Roodpeyma, S.; Taherzadeh, M. J., (2007). Ethanol production from bread residues. Biomass Bioenerg., 32 (4), 333-337 (5 pages).

Gaspar, M.; Kalman, G.; Reczey, K., (2007). Corn fiber as a raw material for hemicellulose and ethanol production. Proc. Biochem., 42 (7), 1135-1139 (5 pages).

Iranmahboob, J.; Nadim, F.; Monemi, S., (2001). Optimizing acid-hydrolysis: a critical step for production of ethanol from mixed wood chips. Biomass Bioenerg., 22 (5), 401404 (5 pages).

Jo, M. S.; Rene, E. R.; Kim, S. H.; Park, H. S., (2008). An analysis of synergistic and antagonistic behavior during BTEX removal in batch system using response surface methodology. J. Hazard. Mater., 152 (3), 1276-1284 (9 pages).

Kádár, Z.; Szengyel, Z.; Reczey, K., (2004). Simultaneous saccharification and fermentation (SSF) of industrial wastes for the production of ethanol. Ind. Crop Prod., 20 (1), 103110 (8 pages).

Kim, J. K.; Han, G. H.; Oh, B. R.; Chun, Y. N.; Eom, C. Y.; Kim, S. W., (2008). Volumetric scale-up of a three stage fermentation system for food waste treatment. Bioresour. Tech., 99 (10), 4394-4399 (6 pages).

King, F. G.; Hossain, M. A., (1982). The effect of temperature, $\mathrm{pH}$, and initial glucose concentration on the kinetics of ethanol production by Zymomonas mobilis in batch fermentation. Biotech. Lett. 4 (8), 531-536 (6 pages).

Le Man, H.; Kim, J. W.; Park, H. S., (2008). Optimization of ethanol production from Korean food waste leachate using response surface methodology. In Korea Society of Waste Management conference, Sunchon University, Sunchon, Republic of Korea 8-10 May.

Lee, D. H.; Behera, S. K.; Won, J. W.; Park, H. S., (2009). Methane production potential of leachate generated from Korean food waste recycling facilities: A lab-scale study. Waste Manage., 29 (2), 876-882 (7 pages).

McMeckin, T. A.; Olley, J.; Ratkwsky, D. A.; Ross, T., (2002). Predictive microbiology: towards the interface and beyond. Int. J. Food Microbiol., 73 (2-3), 395-407 (12 pages).

McMillan, J. D. (1997). Bioethanol production: Status and prospects. Renew Energ., 10 (2), 295-302 (8 pages).

Miller, G. L., (1959). Use of DNS reagent for determination of reducing sugars. Anal. Chem., 31, 426-428 (3 pages).

Muralidhar, R.; Gummadi, S. N.; Dasu, V. V.; Panda, T., (2003). Statistical analysis on some critical parameters affecting the formation of protoplasts from the mycelium of Penicillium griseofulvum. Biochem. Eng. J., 16 (3), 229235 ( 7 pages).

Nahvi, I.; Emtiaxi, G.; Alkabi, L., (2002). Isolation of a flocculating Saccharomyces cerevisiae and investigation of its performance in the fermentation of beet molasses to ethanol. Biomass Bioenerg., 23 (6), 481-486 (6 pages).

Nigam, J. N., (2000). Continuous ethanol production from pineapple cannery waste using immobilized yeast cells. J. Biotech., 80 (2), 189-193 (5 pages).

Ozmihci, S.; Kargi, F., (2007). Effects of feed sugar concentration on continuous ethanol fermentation of cheese whey powder solution (CWP). Enzyme Microb. Tech., 41 (6-7), 876-880 (5 pages). 
Pena, A.; Cinco, G.; Gomez-Puyou, A.; Tuena, M., (1972). Effect of the $\mathrm{pH}$ of the incubation medium on glycolysis and respiration in Saccharomyces cerevisiae. Arch. Biochem. Biophys., 153 (2), 413-425 (13 pages).

Phisalaphong, M.; Srirattana, N.; Tanthapanichakoon, W., (2005). Mathematical modeling to investigate temperature effect on kinetic parameters of ethanol fermentation. Biochem. Eng. J., 28 (1), 36-43 (8 pages).

Ratnam, B. V. V.; Rao, M. N.; Rao, M. D.; Rao, S. S.; Ayyanna, C., (2003). Optimization of fermentation conditions for the production of ethanol from sago starch using response methodology. World J. Microb. Biot., 19 (5), 523-526 (4 pages).

Ravikumar, K.; Pakshirajan, K.; Swaminathan, T.; Balu, K., (2005). Optimization of batch process parameters using response surface methodology for dye removal by a novel adsorbent. Chem. Eng. J., 105 (3), 131-138 (8 pages).

Rene, E. R.; Jo, M. S.; Kim, S. H.; Park, H. S., (2007). Statistical analysis of main and interaction effects during the removal of BTEX mixtures in batch conditions, using wastewater treatment plant sludge microbes. Int. J. Environ. Sci. Tech., 4 (2), 177-182 (6 pages).
Rivera, E. C.; Costa, A. C.; Atala, D. I. P.; Maugeri, F.; Maciel, M. R. W.; Filho, R. M., (2006). Evaluation of optimization techniques for parameter estimation: Application to ethanol fermentation considering the effect of temperature. Proc Biochem., 41 (7), 1682-1687 (6 pages).

Tang, Y. Q.; Koikem, Y.; Liu, K.; An, M. Z.; Morimura, S.; Wu, X. L.; Kida, K., (2008). Ethanol production from kitchen waste using the flocculating yeast Saccharomyces cerevisiae strain KF-7. Biomass Bioenerg., 32 (11), 10371045 (9 pages).

Teixeira, L. C.; Linden, J. C.; Schroeder, H. A., (1999). Optimizing peracetic acid pretreatment conditions for improved simultaneous saccharification and co-fermentation (SSCF) of sugar cane bagasse to ethanol fuel. Renew. Energ., 16 (1-4), 1070-1073 (4 pages).

Wang, Q.; Ma, H.; Xu, W.; Gong, L.; Zhang, W.; Zou, D., (2008). Ethanol production from kitchen garbage using response surface methodology. Biochem. Eng. J., 39 (3), 604-610 (7 pages).

Wilkins, M. R.; Widmer, W. W.; Grohmann, K., (2007). Simultaneous saccharification and fermentation of citrus peel waste by Saccharomyces cerevisiae to produce ethanol. Proc. Biochem., 42 (12), 1614-1619 (6 pages).

\section{AUTHOR (S) BIOSKETCHES}

Le Man, H., M.Sc., Department of Civil and Environmental Engineering, University of Ulsan, South Korea. Email: huynh_leman@yahoo.com

Behera, S. K., Ph.D. Candidate, Department of Civil and Environmental Engineering, University of Ulsan, South Korea. Email: shishir.kb@gmail.com

Park, H. S., Ph.D. P.E., Full Professor, Department of Civil and Environmental Engineering and Director of the Ecosystems Laboratory, University of Ulsan, South Korea. Email: parkhs@ulsan.ac.kr 